\title{
Loss of bone mineral density in premenopausal women with systemic lupus erythematosus
}

\author{
F Formiga, I Moga, J M Nolla, M Pac, F Mitjavila, D Roig-Escofet
}

\begin{abstract}
Objective-To evaluate bone mineral density (BMD) in premenopausal patients with systemic lupus erythematosus (SLE). Methods-We measured BMD by dual energy $x$ ray absorptiometry at lumbar vertebrae L2-4 and at the right femoral neck in 74 premenopausal white patients (mean age 30.8 years) with SLE who were receiving glucocorticoid therapy, and in a control group.

Results-The mean cumulative dose of prednisone was $32 \cdot 5$ (SD 28) g. The mean dose at the time of absorptiometry was 13.7 (6.9) mg. BMD was significantly reduced at the spine and at the femoral neck in SLE patients when compared with the control group: L2-4 $=0.943(0.1) \mathrm{g} / \mathrm{cm}^{2}$ $v 1.038(0.1) \mathrm{g} / \mathrm{cm}^{2} \quad(\mathrm{p}<0.001)$; femoral neck $=0.766(0.09) \mathrm{g} / \mathrm{cm}^{2} v 0.864(0.1) \mathrm{g} / \mathrm{cm}^{2}$ $(p<0.001)$. Nine patients $(12 \cdot 1 \%)$, but none of the control group, had a BMD less than the reference range.

Conclusion-BMD in premenopausal patients with SLE was less than that in a control group and less than the reference range of values defining the presence of osteoporosis in $12 \cdot 1 \%$. We did not find a relationship between BMD and either cumulative or baseline dose of corticosteroid therapy.
\end{abstract}

(Ann Rheum Dis 1995; 54: 274-276)

Systemic lupus erythematosus (SLE) is an inflammatory disease resulting in multisystem damage. The clinical course is characterised by periods of remission and relapses. It mainly affects women in their reproductive years, and they often have irregular menstrual cycles. Most of the patients need glucocorticoid therapy to control the disease activity.

These factors suggest that osteoporosis is likely to be a complication in SLE. Surprisingly, there are few reports on bone mineral density (BMD) in SLE. ${ }^{12}$ The aim of the present study was to analyse BMD in a population of premenopausal SLE patients receiving glucocorticoid therapy.

\section{Patients and methods}

We followed closely the clinical course of 150 white patients who fulfilled at least four American Rheumatologists Association criteria for SLE. ${ }^{3}$ We evaluated all the premenopausal patients and included in the study 74 patients who fulfilled the following criteria: age greater than 16 years; one year or more of evolution of the disease; glucocorticoid therapy received at some stage of the disease; serum creatinine concentrations $<1.3 \mathrm{mg} / \mathrm{dl}$; no coexisting condition (intestinal malabsorption, liver disease, hyperparathyroidism) that could interfere with bone metabolism; no previous or current therapy with drugs known to affect bone metabolism (including anticonvulsants, barbiturates, oestrogenic hormones, androgenic hormones, sodium fluoride, calcitonin, supplementary calcium, thiazide or anticoagulant drug therapy); functional class I or II according to Steinbrocker et $a l ;{ }^{4}$ no significant history of alcohol consumption; no history of smoking, or fewer than 100 cigarettes in their lifetime.

The following data were recorded: age; age at onset of disease; duration of disease (months); cumulative dose of corticosteroids (prednisone or equivalent); dose of corticosteroids at the time that densitometry was performed (prednisone or equivalent); mean dose of corticosteroids/year; disease activity of the lupus patients, assessed with the University College Hospital/Middlesex SLE scoring system $^{5}$ with a numerical score of disease activity graded from 1 to 4 (inactive to severely active disease); presence of 12 or more months of amenorrhoea (the periods of amenorrhoea not necessarily concurrent; information was sought concerning lack of bleeding during periods of at least 3 months duration); calcium intake (dietician's estimate based on review of food consumption during the eight weeks before testing).

The control group comprised 50 premenopausal women who were volunteers taking part in a screening programme of age related bone loss. They had similar age, weight, and height distribution, and regular menstrual cycles. Those with diseases or treatments that could interfere with bone metabolism were excluded.

Using ultrasensitive film in order to minimise the exposure to $x$ rays, we obtained anteroposterior and lateral radiographs of the thoracic and lumbar spine, and anteroposterior radiographs of the hip in all the SLE patients and the control group.

In both groups of subjects, BMD in the lumbar spine and femoral neck was measured by dual energy $x$ ray absorptiometry (DXA) using a densitometer (Hologic QDR 1000). The regions of interest analysed in the lumbar spine were L2, L3, and L4 (giving a mean value for L2-4); in the right hip, the femoral neck was chosen. Calibration of the technique against a lumbar spine phantom was performed daily and with a femoral phantom 
weekly; measurement of bone mineral content was accurate to within $0.5 \%$ compared with the Hologic X-caliber QDR-1 Anthropomorphic Spine Phantom of known mineral content, and precision of measurement was better than $0.01 \mathrm{~g} / \mathrm{cm}^{2}$ (coefficient of variation $1.0 \%$ at $\left.\mathrm{BMD} 1.0 \mathrm{~g} / \mathrm{cm}^{2}\right)$. Patients received doses of radiation in the range $2-5$ mrem $(0.02-0.05 \mathrm{SV})$ per scan.

According to established criteria, ${ }^{6}$ we defined osteoporosis as present when the BMD of the lumbar spine was $2 \mathrm{SD}$ less than the mean of that age group which includes subjects 20-40 years old, utilising the results of a multicentre Spanish study of 2442 patients (1305 women), analysed by DXA. The relevant reference value for $\mathrm{L} 2-4$ was $<0.793 \mathrm{~g} / \mathrm{cm}^{2}$.

Vertebral fracture was defined as a reduction of at least $20 \%$ in anterior height compared with posterior height.

Results were expressed as mean (SD) and were analysed by $\mathrm{Z}$ test. Multiple linear regression was used for analysis of BMD of lumbar spine and femoral neck with cumulative dose and dose at the time of DXA. Results were considered significant when $\mathrm{p}<0.05$.

\section{Results}

The mean age of the 74 SLE premenopausal patients was $30.8(6.5)$ years (range 17-44 years), mean age at disease onset was 23.6 (7.6) years (range 11-43 years), and mean duration of disease was $86 \cdot 4(60 \cdot 7)$ months. In the control group the mean age was $30 \cdot 8(6 \cdot 9)$ years (range $16-44$ years).

The mean cumulative dose of prednisone was $32.5(28.5) \mathrm{g}$ (range $2 \cdot 7-116.4 \mathrm{~g}$ ), with an average of $4.5 \mathrm{~g} /$ year (mean daily dose $12.32 \mathrm{mg}$ ). The mean dose at the time of absorptiometry was $13.7(6.9) \mathrm{mg} /$ day (range $0-50 \mathrm{mg} /$ day $)$. Fifty four patients $(72.9 \%)$ were receiving alternate day therapy.

Three patients $(4 \%)$ had 12 or more months of amenorrhoea.

Mean dietary calcium intake in all the SLE patients was $955(400) \mathrm{mg}$ per day. At the time of DXA the mean disease activity grade was $2 \cdot 43(0 \cdot 7)$

No patient or control had vertebral fractures.

BMD was significantly decreased at the spine and the femoral neck in SLE patients compared with the control group (table 1): L2-4 0.943 $(0.1) \mathrm{g} / \mathrm{cm}^{2}$ v $1.038(0.1) \mathrm{g} / \mathrm{cm}^{2}$ $(\mathrm{p}<0.001)$; femoral neck $0.766(0.09) \mathrm{g} / \mathrm{cm}^{2} v$ $0.864(0.1) \mathrm{g} / \mathrm{cm}^{2}(\mathrm{p}<0.001)$.

Among the SLE patients, nine $(12 \cdot 1 \%)$ had BMD below the reference range for young females which defined osteoporosis; one of these nine had amenorrhoea. In the control group none had BMD values below the reference range. There were no statistical differences between the variables studied in the nine SLE patients with osteoporosis compared with the 65 SLE patients without osteoporosis.

There was no correlation between the dose of prednisone at the time of densitometry or the cumulative dose and $\mathrm{BMD}$ at the lumbar spine or femoral neck, and no difference in BMD between patients receiving daily or alternate day steroid therapy.

We did not find correlation between disease duration or mean disease activity grade and BMD.

\section{Discussion}

Most studies of osteoporosis in patients with autoimmune disease have been in those with rheumatoid arthritis. ${ }^{7-10}$ There has been little investigation of osteoporosis in patients with SLE. ${ }^{2} 211$

Our study using dual energy $x$ ray absorptiometry has shown a high percentage of patients with low BMD in a population of 74 SLE young, premenopausal subjects: nine of our patients $(12 \cdot 1 \%)$ had BMD below the reference range indicating osteoporosis. We found the bone mass of the lumbar spine and femoral neck to be less in this group of SLE patients than in control subjects $(p<0.001)$. Fractures were not found. Our patients had a high mean cumulative dose of prednisone and a high mean dose of prednisone at the time of the study, but we did not find any relation between dose of glucocorticoid therapy and BMD in the lumbar spine or femoral neck. In addition, we did not find any correlation between BMD and disease duration or the disease activity.

Our results confirm those of Dhillon et al ${ }^{1}$ and Kalla $e t \mathrm{al}^{2}$ in premenopausal SLE patients, which also showed no correlation between cumulative dose of prednisone and BMD, and no fractures. However, Dhillon et $a l^{1}$ found a lower frequency of osteoporosis, reporting a low BMD in one $(4.5 \%)$ of 22 SLE patientsadmittedly a small sample size. In the more recent report of Kalla et $a l,{ }^{2} 25 \%$ of 46 SLE patients had BMD below the reference range.

Glucocorticoid therapy, ${ }^{12}$ amenorrhoea, ${ }^{13}$ hyperparathyroidism secondary to chronic renal failure, ${ }^{14}$ conscious avoidance of sunshine, immobility as a result of arthritis, and the disease itself are the most likely contributing factors in osteoporosis associated with SLE.

The pathogenesis of glucocorticoid induced osteoporosis involves inhibition of intestinal calcium absorption ${ }^{15-17}$ and increased urinary calcium excretion, ${ }^{18}$ causing secondary hyperparathyroidism. ${ }^{19}$ There is also inhibition of bone formation ${ }^{20}$ with enhanced bone resorption, ${ }^{21}$ and decreasing gonadal steroid secretion. ${ }^{22} 23$ Bone loss is most rapid in areas of the skeleton containing the greatest proportion of trabecular bone. ${ }^{24}$ While the exact incidence of osteoporosis in patients receiving glucocorticoid therapy remains unknown, figures of $30-50 \%$ have been reported. ${ }^{25} 26$ The dose of prednisone that inhibits bone formation has not been identified.

Amenorrhoeic young women participating in intensive exercise, and those with anorexia nervosa, ${ }^{13}$ hypogonadotrophic hypogonadism, ${ }^{27}$ hyperprolactinaemia, ${ }^{28}$ or premature menopause $^{29}$ also have reduced bone mass. Some studies $^{3031}$ have suggested that factors 
produced in the inflammatory mechanism of SLE may be implicated in disturbances of bone mineral metabolism which lead to osteoporosis. Tanaka et $a l^{31}$ observed spontaneous production of bone resorbing lymphokines in SLE patients in the absence of corticosteroid therapy. In view of their own results and the observation of Lahita et $a l^{32}$ of increased rates of 16- $\alpha$ hydroxylation of oestradiol in lupus patients with the formation of oestrogenic metabolites such as 16- $\alpha$ hydroxyoestrone and oestriol, Dhillon et al ${ }^{1}$ suggested the possibility that lupus patients may be protected from osteoporosis.

Although none of our patients showed symptomatic fracture, they had lower BMD values than the normal controls. Because a low BMD predicts an increased risk for bone fractures, and because of the young age of our group (premenopausal patients), we believe that osteoporosis may become a serious problem for these patients in the future, when they reach menopause. Prophylactic strategies are needed for this group.

1 Dhillon V B, Davies M C, Hall M L, et al. Assessment of the effect of oral corticosteroids on bone mineral density in systemic lupus erythematosus: a preliminary study with dual energy $x$ ray absorptiometry. Ann Rheum Dis 1990 49: 624-6.

2 Kalla A A, Fataar A B, Jessop S J, Bewerunge L. Loss of trabecular bone mineral density in systemic lupus trabecular bone mineral density in systemic

3 Tan E M, Cohen A S, Fries J F, et al. The 1982 revised criteria for the classification of systemic lupus criteria for the classification of systemic

4 Steinbrocker O, Traeger C H, Batterman R E. Therapeutic criteria in rheumatoid arthritis. $\mathscr{A} A M A$ 1947; 140: 659-67.

5 Isenberg D A, Shoenfeld Y, Schwartz R S. Multiple serologic reactions and their relationship to clinical activity in systemic lupus erythematosus. Arthritis Rheun 1984; 27 : $132-8$

6 Nordin B E C. The definition and diagnosis of osteoporosis. Calcif Tissue Int 1987; 40: 659-62.

7 Sambroock P, Eisman J, Yeates M, Pocock N, Eberl S, Champion C. Osteoporosis in rheumatoid arthritis: safety of low dose corticosteroids. Ann Rheum Dis 1986; 45: of low

8 Compston J E, Crawley E O, Evans C, O'Sullivan M M Spinal trabecular bone mineral content in patients with
non-steroid treated rheumatoid arthritis. Ann Rheum Dis non-steroid treated

9 Leboff M S, Wade J P, Mackowiack S, Fuleihan G E H, Zangari $M$, Matthew $\mathrm{H}$ L. Low dose prednisone does not affect calcium homeostasis or bone density in postmenopausal women with rheumatoid arthritis. 7 Rheumatol 1991; 18: 339-44.

10 Van den Brink $H$ R, Lems W F, Van Everdingen A A Bijilsma J W J. Adjuvant oestrogen treatment increases bone mineral density in postmenopausal women with bone mineral density in postmenopausal women

11 Reed A, Haugen M, Patchman L M, Langman C B. Abnormalities in serum osteocalcin values in children Abnormalities in serum osteocalcin values in children
with cronic rheumatic diseases. F Pediatr 1990; 116: with cronic

12 Dykman T R, Gluck O S, Murphy W A, Hahn T J Hahn B H. Evaluation of factors associated with gluco- corticoid induced osteopenia in patients with rheumatic diseases. Arthritis Rheum 1985; 28: 361-8.

13 Rigotti N A, Neer R N, Steven J S, Herzog M D Nussbaum S R. The clinical course of osteoporosis in anorexia nervosa: the longitudinal study of cortical bone mass. fAMA 1991; 265: 1133-8.

14 Babini S M, Arturi A, Marcos J C, Babini J C, Iniguez $\mathrm{A} M$, Morteo $\mathrm{O} G$. Laxity and rupture of the patellar tendon in sýstemic lupus erythematosus: association with secondary hyperparathryoidism. 7 Rheumatol 1988; 15: 1162-5.

15 Colette C, Monnier L, Pares Herbute N, Blotman F, Mirouze J. Calcium absorption in corticoid treated subjects effects of a single oral dose of calcitriol. Horm Metab Res 1987; 19: 335-8.

16 Klein R G, Arnaud S B, Gallagher J C, DeLuca H F Riggs B L. Intestinal calcium absorption in exogenous
hypercortisonism. Role of 25 -hydroxyvitamin $\mathrm{D}$ and hypercortisonism. Role of 25-hydroxyvitamin

17 Hahn T J, Halstead L R, Baran D T. Effects of short term glucocorticoid administration on intestinal calcium absorption and circulating vitamin D metabolite concentration in man. $\mathcal{F}$ Clin Endocrinol Metab 1981; 52: $111-5$.

18 Reid I R, Ibbertson H K. Evidence of decreased tubular reabsorption of calcium in glucocorticoid-treated asthmatics. Horm Res 1987; 27: 200-4.

19 Suzuki Y, Ichinawa Y, Saito E, Homma M. Importance of increased urinary calcium excretion in the development of secondary hyperparathyroidism of patients under glucocorticoid therapy. Metabolism 1983; 32: 151-6.

20 Bressot C, Meunier P J, Chapuy M C, Lejeune E, Edouard C, Darby A J. Histomorphometric profile, pathophysiology and reversibility of corticosteroid-induced osteoporosis. Metab Bone Relat Res 1979; 1: 303-1

21 Meunier P J, Bressot C. Endocrine influences on bone cells and bone remodeling evaluated by clinical histomorphometry. In: Parsons J, ed. Endocrinology of calcium metabolism. New York: Raven Press, 1982: 445-65.

22 Sambrook P N, Eisman J A, Champion G D, Pocock N A Sex hormone status and osteoporosis in postmenopausal women with rheumatoid arthritis. Arthritis Rheum 1988, 31: $973-8$.

23 Goulding A, Gold E. Effects of chronic prednisolone treatment on bone resorption and bone composition in intact and ovariectomized rats and in ovariectomized rats receiving B-estradiol. Endocrinology 1988; 122: 482-7.

24 Blukert B P, Raisz L G. Glucocorticoid-induced osteoporosis: pathogenesis and management. Ann Intern Med 990; 112: 352-64.

25 Adinoff A D, Hollister J R. Steroid-induced fractures and bone loss in patients with asthma. $N$ Engl f Med 1983 309: $265-8$

26 Ruegsegger P, Medici T C, Anliker M. Corticosteroidinduced bone loss. A longitudinal study of alternate day therapy in patients with bronchial asthma using quantitative computed tomography. Eur 7 Clin Pharmacol 1983; 25: 615-20.

27 Jackson J A, Leerekoper $M$. Osteoporosis in men Diagnosis, pathophysiology and prevention. Medicine 1990; 69: 137-52.

28 Greenspan S L, Opperheim D S, Klibansky A. The importance of gonodal steroids to bone mass in men with importance of gonodal steroids to bone mass in men with 110: $526-31$.

29 Richelson L S, Wahner H W, Melton L J III, Riggs B L. Relative contributions of aging and estrogen deficiency to postmenopausal bone loss. $N$ Engl f Med 1984; 311 1273-5.

30 Seitz M, Hunstein W. Enhanced prostanoid release from monocytes of patients with rheumatoid arthritis and active systemic lupus erythematosus. Ann Rheum Dis 1985; 44: 438-45.

31 Tanaka Y, Watanabe K, Suzuki M, et al. Spontaneous production of bone-resorbing lymphokines by B cells in patients with systemic lupus erythematosus. $f$ Clin patients with systemic

32 Lahita $R$ G, Bradlow $H$ L, Fishman J, Kunkel $H$ G. Abnormal oestrogen and androgen metabolism in the Abnormal oestrogen and androgen metabolism in the Dis 1982; 2 (suppl 1): 206-11. 